\title{
Giant Omphalocele Ruptured: An Operated Case and Review of the Literature
}

\author{
Koffi Maxime Koffi ${ }^{*}$, Akaffou Evelyne ${ }^{2}$, Dieth Atafy Gaudens ${ }^{1}$, Yapo Brouh ${ }^{3}$, \\ da Silva-Anoma Sylvia ${ }^{1}$
}

${ }^{1}$ Pediatric Surgery, Mother and Children Hospital of Bingerville, Bingerville, Côte d'Ivoire ${ }^{2}$ General Pediatric, Mother and Children Hospital of Bingerville, Bingerville, Côte d'Ivoire

${ }^{3}$ Anesthesiology, Mother and Children Hospital of Bingerville, Bingerville, Côte d'Ivoire

Email: *koffimaxime@gmail.com

How to cite this paper: Koffi, K.M., Evelyne, A., Gaudens, D.A., Brouh, Y. and Sylvia, da S.-A. (2020) Giant Omphalocele Ruptured: An Operated Case and Review of the Literature. Open Journal of Pediatrics, 10, 447-451.

https://doi.org/10.4236/ojped.2020.103045

Received: June 19, 2020

Accepted: September 1, 2020

Published: September 4, 2020

Copyright $\odot 2020$ by author(s) and Scientific Research Publishing Inc. This work is licensed under the Creative Commons Attribution International License (CC BY 4.0).

http://creativecommons.org/licenses/by/4.0/

\section{(c) (i) Open Access}

\begin{abstract}
Background: The omphalocele is a congenital defect of closure of the abdominal wall at the level of the umbilical ring with evisceration of the intra-abdominal organs in the form of a bag covered with a membrane. This membrane can rupture and become an extreme emergency that can put the infant's life at stake. Aim: The purpose of this case report is to present a case of ruptured omphalocele operated successfully and describe the factors of good prognosis. Case Presentation: A female new-born with a giant omphalocele. This omphalocele ruptured during conservative treatment. An emergency surgery was organised and the defect was closed by using a prosthesis. The postoperative course was simple. During the 12 months follow-up, we have seen no complication. Conclusion: The management of ruptured omphaloceles is a surgical and anesthetic challenge. The mortality of this condition can be improved in our context by setting up well-equipped neonatal resuscitation units.
\end{abstract}

\section{Keywords}

Ruptured Omphalocele, Surgery, Tanning

\section{Introduction}

Omphalocele is a congenital defect in the closure of the abdominal wall at the level of the umbilical ring with evisceration of the intra-abdominal organs in the form of a bag covered with a three-layer membrane: the peritoneum, Wharton's jelly and amnion [1]. Omphalocele is said to be giant when the diameter is greater than $5 \mathrm{~cm}$ or when the bag contains the liver [2]. This form is accompa- 
nied by hypoplasia of the abdominal wall, the immediate closure can create an abdominal hyperpressure responsible for respiratory distress [3]. The membrane covering the herniated loops is liable to rupture, thus transforming this condition into a real surgical emergency involving the life-threatening prognosis of the newborn. We report a case of ruptured giant omphalocele successfully operated, and we analyze the prognostic factors.

\section{Case Study}

K. A female, born at term, after a well-followed pregnancy, by elective cesarean section for prenatal diagnosis of omphalocele. At birth, it was a type II omphalocele (Figure 1). It measured $7 \mathrm{~cm}$ in diameter and $14 \mathrm{~cm}$ in height, the liver was present in the bag. The newborn weighed 3120 grams. There was no visible macroglossia or bone malformation. The blood sugar was normal. The patient was hospitalized in neonatal, incubator and conservative treatment by tanning with $2 \%$ aqueous eosin was started. On the fifth day of hospitalization, there was a rupture of the membrane. Surgical intervention was organized urgently. The operating team consisted of a senior anesthesiologist and two senior pediatric surgeons. Peroperatively, the liver presented a ballooned appearance. Reintegration of the external viscera was carried out and the abdominal wall was closed in one step with the placement of a prolene prosthesis. The patient was in intensive care for 5 days. The post-operative follow-up was simple: extubation was done 11 hours after waking up, feeding allowed on the second day. The patient was discharged on the fifth day of surgery. With a one-year follow-up, clinical follow-up is unremarkable and renal ultrasounds are normal (Figure 2).

\section{Discussion}

Omphalocele is a rare congenital pathology as evidenced by its low incidence which varies from $1 / 4000$ to $1 / 7000$ live births [4]. It is a pathology accessible to prenatal diagnosis. For some authors, when the diagnosis is made in antenatal,



Figure 1. Omphalocele type II. 


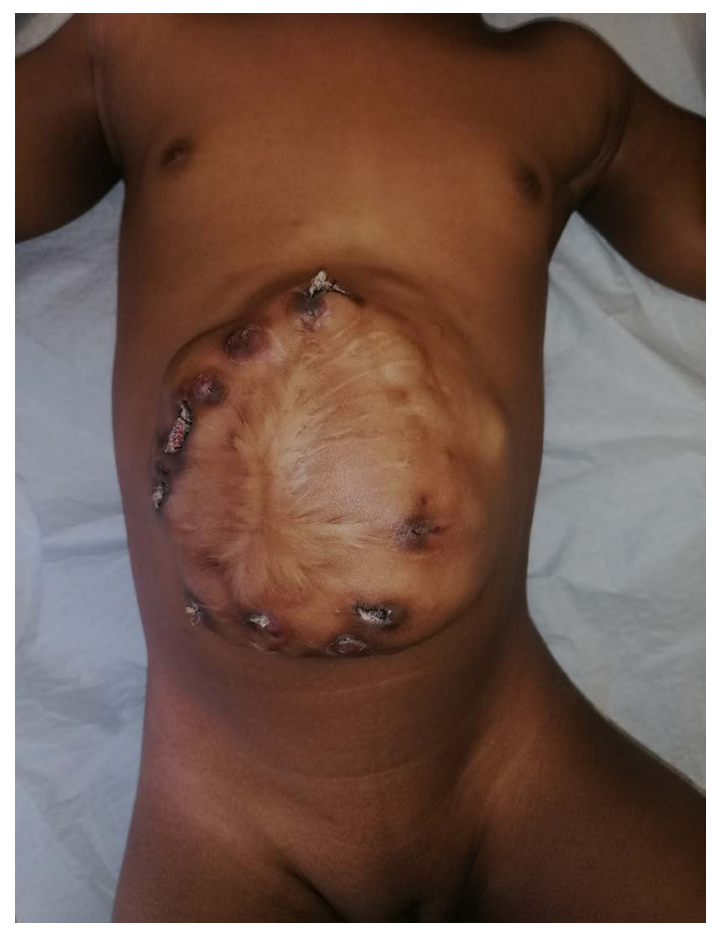

Figure 2. Complete healing.

the delivery must be done by cesarean section [5] [6]. In the case of a giant omphalocele, the cesarean section is used to prevent rupture of the sac and/or rupture of the liver [5] [6].

The rupture of the omphalocele can occur at different times: during childbirth, during transport of the newborn, or during care. In utero rupture has even been described [7]. In our case, we don't know exactly when the rupture occurred. It was discovered by the nurse. The rupture of the sac is described by N'Dour et al. as one of the detrimental factors of poor prognosis for newborns with a giant omphalocele [8].

The treatment of giant omphaloceles is still controversial. In developed countries, surgery is systematic [9]. In our context, this surgery is only reserved for small omphaloceles or in cases of rupture of the sac. This is due to the absence of a technical platform allowing effective neonatal resuscitation with continuous respiratory assistance.

The reintegration of the external viscera into an underdeveloped abdominal cavity has hemodynamic and respiratory consequences which it is important to consider for the surgical decision. Immediate wall closure by simple wall alignment is risky. It can hinder the hemodynamic state and hematosis of the newborn [10]. It requires mechanical ventilation with curarization in per and postoperative [10]. A well-equipped pediatric resuscitation unit is mandatory.

Several surgical techniques are described in the literature: progressive reintegration through the use of silos [11]; reintegration in one time with the use of an absorbable [12] or non-absorbable prosthesis [13]; in our case, a nonabsorbable prosthesis was used. The prosthesis has indeed revolutionized the prognosis of 
giant omphaloceles.

Mortality of omphaloceles of all types remains high in the African series: 45.3\% in Dakar [8], 30\% in Abidjan [14] and 18.03\% in Bamako [15]. This mortality is increased in the event of rupture: $100 \%$ death [15]. This high mortality rate is explained by the absence of a neonatal intensive care unit equipped with advanced equipment.

Several factors were involved in obtaining the right result in this case. These are: the isolated nature of the malformation, the right birth weight, the rupture of the sac in a benchmark neonatal service where the ecosystem is under control, the rules of hygiene are respected and care is of quality, speed care by a multidisciplinary senior team (pediatric neonatologist, pediatric surgeon and anesthesiologist), the availability of the prosthesis and the quality of the technical platform.

\section{Conclusion}

The management of ruptured giant omphaloceles is a surgical as well as anesthetic challenge. The mortality of this condition can be improved in our context by setting up well-equipped neonatal resuscitation units.

\section{Informed Consent}

Informed consent was obtained from the patient's parent to report this case.

\section{Conflicts of Interest}

The authors declare no conflicts of interest regarding the publication of this paper.

\section{References}

[1] Pandey, V., Gangopadhyay, A.N., Gupta, D.K., Sharma, S.P. and Kumar, V. (2014) Non-Operative Management of Giant Omphalocele with Topical Povidone-Iodine and Powdered Antibiotic Combination: Early Experience from a Tertiary Centre. Pediatric Surgery International, 30, 407-411. https://doi.org/10.1007/s00383-014-3479-9

[2] Campos, B.A., Tatsuo, E.S. and Miranda, M.E. (2009) Omphalocele: How Big Does It Have to Be a Giant One? Journal of Pediatric Surgery, 44, 1474-1475. https://doi.org/10.1016/j.jpedsurg.2009.02.060

[3] Andriamanarivo, M.L., Hunald, F.A., Rajaonarivony, M.F.V., Raherison, A.R. and Rakotovao, M. (2012) Treatment of Giant Omphalocele in Madagascar. E-mémoires de 1 Académie Nationale de Chirurgie, 11, 48-51.

[4] Tassin, M., Descriaud, C. and Elie, C. (2013) Omphalocele in the First Trimester: Prediction of Perinatal Outcome. Prenatal Diagnosis, 33, 497-501. https://doi.org/10.1002/pd.4102

[5] Vachharajani, A.I., Rao, R., Keswani, S. and Mathur, A.M. (2009) Outcomes of Exomphalos: An Institutional Experience. Pediatric Surgery International, 25, 139-144. https://doi.org/10.1007/s00383-008-2301-y

[6] Duke, D.S. and Schwartz, M.S. (2009) Omphalocele and Gastroschisis. In: Puri, P. 
and Höllwarth, M., Eds., Pediatric Surgery, Springer, Berlin, 619-627. https://doi.org/10.1007/978-3-540-69560-8_63

[7] Aitken, J. (1963) Exemphalos: Analysis of a 10-Year Series of 32 Cases. Archive of Disease in Childhood, 8, 126-129. https://doi.org/10.1136/adc.38.198.126

[8] Ndour, O., Faye Fall, A., Alumeti, D.M., Fall, M., Diouf, C., Ndoye, A., Ngom, G. and Ndoye, M. (2009) Etude des facteurs pronostiques de l'omphalocèle au service de Chirurgie Pédiatrique du CHU Aristide Le Dantec de Dakar: A propos de 95 cas. Rev. CAMES-Série A, 8, 103-106.

[9] Binet, A., Scalabre, A. and Amar, S., (2019) Operative versus Conservative Treatment for Giant Omphalocele: Study of French and Ivorian Management. Annales de Chirurgie Plastique Esthétique, 65, 147-153.

https://doi.org/10.1016/j.anplas.2019.03.004

[10] Lee, S.L., Beyer, T.D., Kim, S.S., Waldhausen, J.H.T. and Healey, P.J. (2004) Initial Nonoperative Management and Delayed Closure for Treatment of Giant Omphaloceles. Journal of Pediatric Surgery, 41, 1846-1849.

https://doi.org/10.1016/j.jpedsurg.2006.06.011

[11] Fischer, J.D. (1995) Gastroschisis: A Simple Technique for Staged Silo Closure. Journal of Pediatric Surgery, 30, 1169-1171. https://doi.org/10.1016/0022-3468(95)90014-4

[12] Baird, R., Gholoum, S., Laberge, J.M. and Puligandla, P. (2010) Management of a Giant Omphalocele with an External Skin Closure System. Journal of Pediatric Surgery, 45, 17-20. https://doi.org/10.1016/j.jpedsurg.2010.05.004

[13] Pacilli, M., Spitz, L. and Kiely, E.M. (2005) Staged Repair of Giant Omphalocele in the Neonatal Period. Journal of Pediatric Surgery, 40, 785-788. https://doi.org/10.1016/j.jpedsurg.2005.01.042

[14] Kouamé, B.D., Dick, R., Ouattara, O., Traoré, A., Gouli, J.C, Dieth, A.G., Da Silva, A. and Roux, C. (2003) Approches thérapeutiques des omphalocèles dans les pays en voie de développement: l'expérience du CHU de Yopougon, Abidjan, Côte-d'Ivoire. Bulletin de la Société de Pathologie Exotique, 96, 302-305.

[15] Kanté, L., Togo, A., Diakité, I., Maiga, A., Traoré, A., Samaké, A., Samaké, H., Dembélé, B.T., Keita, M., Coulibaly, Y. and Diallo, G. (2010) Omphalocele in General and Pediatric Surgeryin Gabriel Touré. Mali Medical, 25, 23-26. 